\title{
Estimating daily global radiation from air temperature and rainfall measurements
}

\author{
M. Bindi, F. Miglietta \\ IATA-CNR, Institute of Environmental Analysis and Remote Sensing for Agriculture, P.le delle Cascine 18, I-50144 Florence, \\ Italy
}

\begin{abstract}
Radiation-mediated processes (e.g. photosynthesis, evapotranspiration) can be simulated on the basis of measured incoming radiation. Since irradiance is measured at very few weather stations it is often estimated from the duration of bright sunshine or from mean daily cloudiness. In the absence of both these variables, irradiance can be estimated by means of satellite images, spatial interpolation techniques or standard meteorological observations. In this paper, a model to estimate daily global radiation from air temperature and rainfall measurements is presented. The model first assesses days on which the probabilities of clear and overcast skies are maximum and predicts, for these days, the mean sky transmittance. The mean sky transmittance can then be interpolated for any other day. In the model, station parameters are directly derived from latitude and ancillary information, so neither historical climatic records nor calibration parameters are required for the calculations. This simplifies to a large extent the estimation procedure. The model was tested for 22 weather stations in 11 countries by comparing estimated and measured irradiance data. Measured and estimated records were also separately used as input of a wheat growth simulation model (NWHEAT) and model results were compared. This comparison showed that when measured irradiance is substituted by estimates there is a very small deviance in the grain yield as calculated by the model.
\end{abstract}

\section{INTRODUCTION}

Daily solar radiation data are often required in agrometeorological calculations, e.g. to compile a water budget for irrigation or to run a crop growth simulation model, but these are measured at few weather stations. When radiation records are not available, these can be estimated by means of an empirical relation using the measured duration of bright sunshine (Black et al. 1954), or cloudiness (van Keulen \& van Heemst 1986). Other methods to estimate the global daily solar radiation have been developed on the basis of satellite remote sensing, of spatial interpolation techniques and on the basis of correlations found between incoming irradiance and other commonly measured weather variables.

Methods that make use of polar orbiting and geostationary satellite data are often very accurate (Tarpley 1979, Diak et al. 1982, Rimòczi-Paàl 1983, Cano et al. 1986, Nuñez 1987, Frulla et al. 1988, Diabatè et al. 1989) but suffer from limitations. The spatial resolution of satellite imagery can be insufficient to achieve good estimates in mountainous regions, the reconstruction of historical solar radiation data is impossible because geostationary and polar orbiting satellites have been operating only since the late seventies, and the common use of satellite images is limited by the high costs of both receiving stations or tapes and image processing hardware.

Spatial interpolation techniques allow estimation of solar radiation at any given point from nearby stations records (Hay \& Suckling 1979, WMO 1981). The accuracy of this method depends on the mean grid size of the radiation measurement network and on the mean variability of weather conditions over the studied region. Weather variability may depend on many factors, especially the orography. Suckling (1985) studied the relationship between the extrapolation distance and the error in radiation estimates due to extrapolation for a large number of climatic regions. He noted that, in central Europe, mean absolute errors due to extrapolation are a linear function of the extrapolation distance and are normally greater than $2 \mathrm{MJ} \mathrm{m}^{-2} \mathrm{~d}^{-1}$.

Standard meteorological observations have already been used to estimate solar radiation and models have been developed for this purpose. Some of these are based on empirical formulae (Atwater \& Ball 1978, Bristow \& Campbell 1984, Hodges et al. 1985, Maracchi 
et al. 1988, McCaskill 1990), while other models involve complex numerical calculations (Cengiz et al. 1981, Richardson 1981). Parameters used as input include air temperature, degree-hours of temperature, relative humidity and rainfall. Historical data (mean annual daily solar radiation, amplitude of annual curves of daily solar radiation, etc.) and geographical data (intercorrelations between daily max. and min. temperatures and solar radiation at a geographical area) are also required.

In this paper a model to estimate daily global radiation on the basis of daily maximum and minimum temperature and total daily rainfall is presented. The model first identifies if a particular day has a high probability of being either completely clear or completely overcast. This is done on the basis of comparison between the daily temperature range (maximum minus minimum) of a given day with the average daily temperature range of a given period. This probability is assumed to increase if rainfall is absent and to decrease if rainfall is present. An estimation of sky transmittance is then made for both days that are identified as clear or overcast and, on the basis of an interpolation technique, also for any other day. Daily global solar radiation is finally calculated as a function of sky transmittance and of calculated extraterrestrial insolation.

The model is validated on the basis of a set of weather data recorded in 11 countries by evaluating the accuracy of global solar radiation estimates. Finally, a model application is illustrated: calculated and measured daily global solar radiation are used separately as input to a wheat growth simulation model (Groot 1987) and model calculations of grain yields compared.

\section{MODEI DESCRIPTION}

The solar radiation that arrives at ground depends on the day of the year, the latitude of the location, and on the atmospheric transmittance $(K)$. On reaching the earth's surface, the incoming radiation is partly reflected and partly absorbed. Net radiation, corresponding to the overall balance of absorbed solar radiation and longwave exchange, is converted to the sum of sensible heat, latent heat and ground heat fluxes. During daytime the earth's surface receives radiative energy and both air and soil temperatures are expected to increase. At night, the surface loses energy by emitting radiation, especially during clear sky conditions. Hence, a clear day is expected to be generally characterized by an increased difference between night and day temperature. On overcast days, the cloudiness reduces the incoming radiation during daytime and also reduces the outgoing radia- tion at night. The difference between night and day temperature is therefore expected to be reduced. Accordingly, the difference between the thermal range of 2 consecutive days is expected to be related to the difference in the mean sky transmittance of the same 2 days.

\section{Identification of clear and overcast days}

Days in which the probability of clear or overcast skies is maximum are firstly recognized. Clear days are identified when the following conditions occur simultaneously:

- maximum temperature increases in respect to the maximum temperature of the day before;

- minimum temperature decreases in respect to the minimum temperature of the day before;

- the temperature range (maximum minus minimum) is greater than the $30 \mathrm{~d}$ moving average of temperature ranges;

- rainfall is absent.

Overcast days are defined by opposite conditions, that is:

- maximum temperature decreases in respect to the maximum temperature of the day before;

- minimum temperature increases in respect to the minimum temperature of the day before;

- the temperature range (maximum minus minimum) is less than the $30 \mathrm{~d}$ moving average of temperature ranges;

- rainfall is present.

In the identification of both clear and overcast days the wind was not considered to have an effect on daily thermal ranges. This assumption was based on analysis of the wind and temperature records of a windy station (Ustica, Italy). The relationship between mean daily wind speed and the daily thermal range at that station. is reported in Fig. 1.

\section{Predicting mean sky transmittance of clear days $(K C)$}

The solar radiation that reaches the earth's surface on a clear day is a function of the solar constant, of the sine of the solar elevation, the relative air mass and the turbidity factor of the air mass. Turbidity, in turn, depends on the transmittance due to molecular (Rayleigh) scattering, to ozone absorption, to the uniformly mixed gases, to water vapour and to aerosols (Justus \& Paris 1985).

If a constant air pressure of $1013 \mathrm{hPa}$ at $0 \mathrm{~m}$ elevation is assumed, the relative air mass is approximately calculated for given location, day of the year and time of day as the reciprocal of the sine of solar height. The 


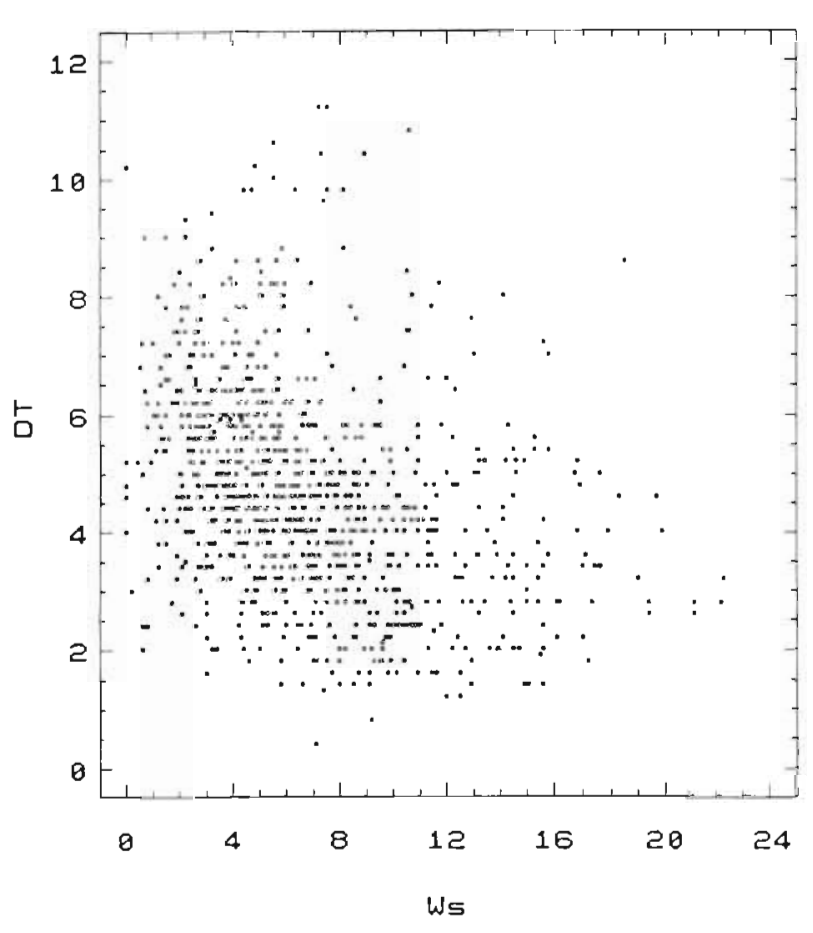

Fig. 1. Relationship between observed mean daily wind speed $(W s)$ and the daily thermal range $(D T)$ calculated for $1000 \mathrm{~d}$ at Ustica (Italy) weather station

turbidity factor (T) is normally calculated from measured incoming radiation by means of Linke's method but it can be also estimated on the basis of an existing correlation between the water content of the atmosphere, i.e. its precipitable water $(w)$, and the turbidity coefficient $(\beta)$ by means of the empirical equation developed by Dogniaux \& Lemoine (1976):

$T]=\left((h+85) /\left(39.5 e^{-w}+47.4\right)+0.1\right)+(16+0.22 w) \beta$

where $h=$ solar elevation (in degrees)

In absence of direct observations, the parameters $w$ and $\beta$ of Eq. (1) can be derived from the following classification of different types of radiation climates by neglecting the effect on these values of air mass conditions:

- polar and desert climates (dry air)

- temperate climates

$w=0.5$ to 1

- tropical climates (humid air)

$w=2$ to 4

- rural site

- urban site

$w=5$

- industrial site

$\beta=0.05$

$\beta=0.1$

$\beta=0.2$

(from Dogniaux \& Lemoine 1982)

When the value of $T 7$ is estimated for a given location for a given day of the year and for a given solar elevation, the sky transmittance of a clear sky is calculated, according to the modified Beer's law equation (Kasten \& Czeplak 1980):

$$
K C_{h}=0.83 \mathrm{e}^{(-0.026 \mathrm{TZ} / \mathrm{sin} h)}
$$

where $K C_{h}=$ the sky transmittance calculated for the solar elevation $h$.

Finally, the mean daily values of $K c$ are found by integrating and averaging $K c_{h}$ over the length of the day. In the model the Gaussian method of integration is used (Goudriaan 1986) as it greatly simplifies computation codes and reduces the computation time.

\section{Predicting mean sky transmittance of overcast days $(\boldsymbol{K o})$}

The sky transmittance on an overcast day mainly depends on the thickness and type of clouds and on the sun elevation (Lumb 1964, Tabata 1964). It is known that high, middle and low clouds attenuate the solar radiation in different ways (Haurwitz 1948, Bennet 1969, Kimura \& Stephenson 1969). A distinction between the fraction of total sky cover (TSC), that is often recorded in synoptic weather stations, and the fraction of cloud cover (cc), that takes into account the attenuation effect of different cloud type groups, was made by Turner \& Abdullaziz (1984). The relationship between these 2 fractions expressed in tenths reported by these authors is given below:

$\mathrm{CC}=\mathrm{TSC}$ for low clouds, middle clouds or low and middle clouds

$\mathrm{cc}=0.5 \mathrm{TSC}$ for high clouds

$\mathrm{CC}=\mathrm{TSC}-0.5$ (Amount of high clouds) for mixed clouds

The model that is illustrated here sets the condition that the 'overcast days' are also rainy days. The rainfall probability of a given day is to some extent related to the cloud type being maximum for Low-Family clouds (Nimbostratus and Stratocumulus) for Middle Clouds (Altocumulus and Altostratus) and for Vertical Clouds (Cumulus and Cumulunimbus). Hence, the cloud cover fraction (cc) on days selected as overcast by the model is assumed to be equal to the maximum sky cover fraction $(\mathrm{cc}=1)$.

Turner \& Abdulaziz (1984) developed an empirical equation to calculate the sky transmittance of overcast days as a function of the solar elevation and the cloud cover fraction. The equation has the following form:

$$
K o_{h}=a+b(\mathrm{cc})^{2} \sin h+c(\mathrm{Cc})^{2}+d \sin h
$$

where $K_{O_{h}}$ is the sky transmittance of an overcast day calculated for the solar elevation $h ; a, b, c, d$ are regression coefficients calculated for different solar elevation (Table 1). In the model the value of the mean daily sky transmittance ( $K o$ ) is calculated by integrating over the day the calculated values of $\mathrm{Ko}_{h}$ according to the Gaussian method. 
Table 1. Regression coefficients for different solar heights (Turner \& Abdulaziz 1984)

\begin{tabular}{rrrrr}
\hline Range of $h$ & $a$ & $b$ & $c$ & $d$ \\
\hline $0^{\circ} \leq h \leq 20^{\circ}$ & 0.3080 & -1.165 & -0.0586 & 1.0743 \\
$20^{\circ}<$ S $40^{\circ}$ & 0.5695 & -0.1065 & -0.4755 & 0.2809 \\
$40^{\circ}<\leq 60^{\circ}$ & 0.7862 & 0.2736 & -0.6943 & -0.0467 \\
$h>60^{\circ}$ & 0.6423 & 0.9109 & -1.2873 & 0.1222 \\
\hline
\end{tabular}

\section{Predicting mean sky transmittance of other days $(\mathrm{Ki})$}

Temperature and rainfall conditions that do not lead to selection of either a completely clear or a completely overcast day, identify an 'intermediate' day. Values of $K i$ for each intermediate day are calculated on the basis of the amplitude of the daily air temperature range and of the sky transmittance of the day before.

The model assumes that the larger the variation in the temperature range of 2 consecutive days, the larger the variation in the mean sky transmittance is expected to be, or, in other words, that the difference between the sky transmittance of 2 consecutive days ( $\left.D K=K_{t}-K_{t-1}\right)$ is directly related to the difference between the temperature ranges of these days (DDT $=$ $\left.D T_{t}-D T_{t-1}\right)$.

The value of $D K$ is assumed to be a function of both $D D T$ and $\mathrm{K}_{t-1}$ according to the response surface illustrated in Fig. 2 and to the set of equations show below:

$$
D K_{t}=\left(K o-K_{t-1}\right) \text { for } D D T_{t}<D D T_{\text {low }}
$$

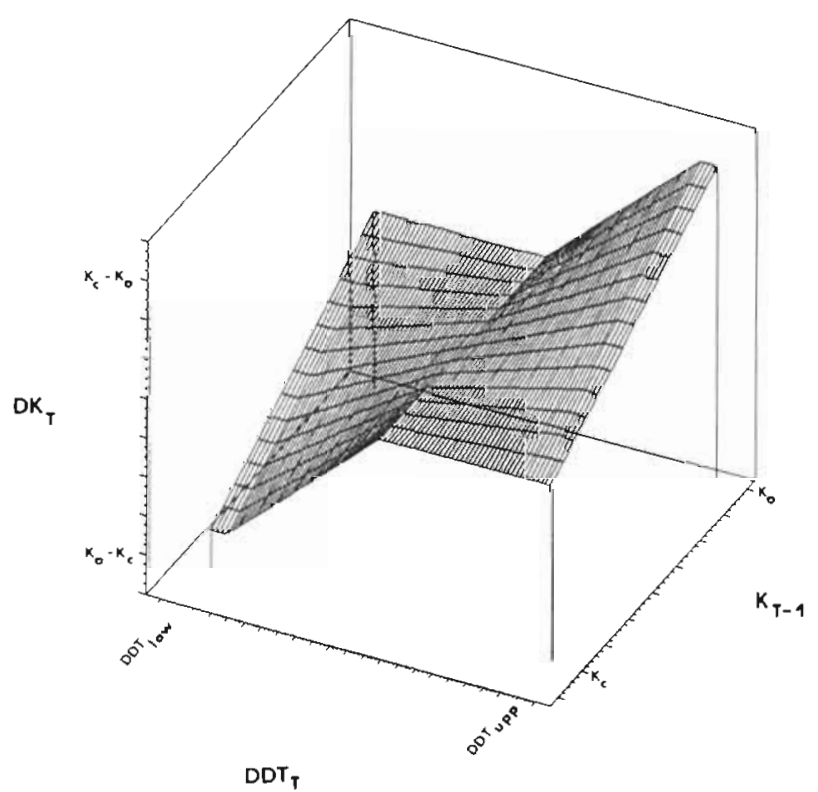

Fig. 2. Relationship between the difference in the temperature ranges $(D D T)$, the mean sky transmittance $\left(K_{t-1}\right)$ and the difference between the sky transmittance of 2 subsequent days $\left(D K_{t}\right)$ as calculated by Eqs. (4), (5), (6) and (7)

$$
\begin{aligned}
& D K_{t}=\left[\left(K o-K_{t-1}\right) / D D T_{\text {low }}\right] D D T_{t} \\
& \text { for } D D T_{\text {low }} \leq D D T_{t} \leq 0 \\
& D K_{t}=\left[\left(K C-K_{t-1}\right) / D D T_{\text {upp }}\right] D D T_{t} \\
& \text { for } 0<D D T_{t} \leq D D T_{\text {upp }} \\
& D K_{t}=\left(K C-K_{t-1}\right) \text { for } D D T_{t}>D D T_{\text {upp }}
\end{aligned}
$$

where $t=$ time in days; $K o, K c=$ values of the mean sky transmittance of respectively an overcast and a clear day calculated for Day $t: D D T_{\text {low }}=$ the lower value of $D D T$ at which $D K$ reaches its minimum; $D D T_{\text {upp }}=$ the upper value of $D D T$ at which $D K$ reaches its maximum.

For each weather station, $D D T_{\text {low }}$ and $D D T_{\text {upp }}$ are calculated by the model using the mean value of $D D T$ calculated for the temperature measurements of one, or possibly, more years, plus or minus 3 times its standard deviation. These boundary values include $98 \%$ of cases by excluding only extreme events that may be to some extent related to extreme weather conditions.

Finally, the mean sky transmittance of Day $t$ is calculated using:

$$
K i_{t}=K_{t-1}+D K_{t}
$$

The calculated mean sky transmittance is used, in the next step, to calculate the sky transmittance of the next day and this operation is repeated until a day that was previously identified as clear or overcast is encountered. When this occurs the value of $K$ is assumed to coincide respectively with $K C$ or $K o$.

\section{Calculation of daily global radiation}

Daily global radiation ( $R s)$ is calculated on the basis of extraterrestrial insolation $(Q)$ and of the mean daily sky transmittance $(K)$ according to the following equation:

$$
R_{S}=Q K
$$

In the equation, parameter $K$ has the value of $K c$ or Ko when a day is identified respectively as clear or overcast and that of $K i$ on intermediate days. The extraterrestrial irradiance at a plane parallel to the earth's surface is calculated according to the procedure formulated by Goudriaan (1977). 
Table 2. Weather stations used for model validation

\begin{tabular}{|c|c|c|c|}
\hline Station & Lat. & Altitude $(\mathrm{m})$ & Years of obs. \\
\hline Bologna, Italy & $44^{\circ} 31^{\prime}$ & 43 & $1958-1978$ \\
\hline Bolzano, Italy & $46^{\circ} 28^{\prime}$ & 237 & $1958-1978$ \\
\hline Brindisi, Italy & $40^{\circ} 40^{\prime}$ & 21 & $1958-1978$ \\
\hline Castana, IA, USA & $42^{\circ} 12^{\prime}$ & 350 & 1979 \\
\hline Gainsville, FL, USA & $29^{\circ} 38^{\prime}$ & 45 & $1978-1979-1981-1985$ \\
\hline Gilat, Israel & $33^{\circ} 20^{\prime}$ & 150 & 1980 \\
\hline Los Baños, Philippines & $14^{\circ} 11^{\prime}$ & 21 & $1980-1981$ \\
\hline Joydebpur, Bangladesh & $23^{\circ} 54^{\prime}$ & 8 & 1983 \\
\hline Le Rheu Rennes, France & $48^{\circ} 04^{\prime}$ & 170 & $1987-1988$ \\
\hline Lethbridge, AL, Canada & $49^{\circ} 25^{\prime}$ & 920 & $1984-1986$ \\
\hline Lubbock, TX, USA & $33^{\circ} 38^{\prime}$ & 1090 & $1984-1986$ \\
\hline Mandan, ND, USA & $46^{\circ} 28^{\prime}$ & 588 & $1984-1986$ \\
\hline Manhattan, KS, USA & $39^{\circ} 05^{\prime}$ & 122 & $1984-1986$ \\
\hline Nayink, China & $32^{\circ} 03^{\prime}$ & 17 & 1983 \\
\hline Palmaria, Colombia & $3^{\circ} 31^{\prime}$ & 1006 & $1983-1985$ \\
\hline Quincy, FL, USA & $30^{\circ} 36^{\prime}$ & 70 & 1979 \\
\hline Samaru, Nigeria & $11^{\circ} 11^{\prime}$ & 686 & $1980-1981$ \\
\hline Sandhills, NE, USA & $41^{\circ} 22^{\prime}$ & 975 & $1984-1986$ \\
\hline Swifterbant, Netherlands & $52^{\circ} 34^{\prime}$ & -4 & $1974-1980$ \\
\hline Ustica, Italy & $38^{\circ} 45^{\prime}$ & 259 & $1958-1978$ \\
\hline Vigna di Valle, Italy & $42^{\circ} 05^{\prime}$ & 270 & $1958-1978$ \\
\hline Wageningen, Netherlands & $51^{\circ} 58^{\prime}$ & 7 & $1958-1978$ \\
\hline
\end{tabular}

In this procedure, the sun declination $(\delta)$ is given by:

$$
\delta=-23.45 \cos (360(t+10) / 365)
$$

where $t=$ number of days since 1 January.

Daylength (Dl) is calculated according to the following equation:

$$
D l=12+24 \arcsin (\tan \phi-\tan \delta) / 180
$$

where $\phi=$ latitude, and the mean sine of solar height $(\sin h)$ is calculated using:

$\sin h=\sin \phi \sin \delta+$

$(24 / \pi) \cos \phi \cos \delta\left(1-(\tan \phi \tan \delta /(\cos \phi \cos \delta))^{2}\right) / D l$

and the extraterrestrial irradiance is finally given by:

$$
Q=D 10.36 \sinh S_{\mathrm{cS}}(1+0.033 \cos (360 t / 365))
$$

where $S_{\mathrm{cs}}=$ solar constant $\left(1370 \mathrm{~J} \mathrm{~m}^{-2} \mathrm{~s}^{-1}\right)$

\section{MODEL VALIDATION}

The model was validated by comparing solar radiation calculated and measured in 22 weather stations from 11 different countries (Table 2). Solar radiation observations were firstly carefully checked and outliers were removed. The mean difference found between calculated and observed radiation and the absolute and relative errors of estimates are given in Table 3 . The same statistics are reported in Table 4 for winter and summer separately.
The accuracy of estimates varies among the different stations and seasons. The mean relative error for the 22 stations is $28.5 \%$ and is higher in winter than in summer $(29.7$ and $26.0 \%$ respectively).

A comparison of model results with the results obtained by means of a spatial interpolation technique (Suckling 1985) is reported in Table 5 for the 6 stations in Italy and one station in The Netherlands. In the table, the absolute errors of model estimates are compared with the absolute errors due to extrapolation. Extrapolation errors were estimated, for each station, on the basis of the distance from the nearest weather station in which radiation is routinely measured, by assuming that the extrapolation error linearly increases with extrapolation distance (Suckling 1985).

Model errors are consistently lower than errors due to extrapolation.

\section{MODEL APPLICATION AND RESULTS}

Solar radiation records are often used in agrometeorological and simulation studies. The recent development of simulation models promises to promote analysis of agricultural production potential and to provide the appropriate technology for achieving this potential over a wide range of conditions (de Wit 1970).

Model estimates and direct measurements of daily global radiation were separately used as input to the wheat growth simulation model NWHEAT (Groot 
Table 3. Mean difference and absolute and relative error computed in the comparison between observed and estimated daily solar radiation

\begin{tabular}{|c|c|c|c|}
\hline Station & $\begin{array}{l}\text { Mean difference } \\
\left(\mathrm{MJ} \mathrm{m}-2 \mathrm{~d}^{-1}\right)\end{array}$ & $\begin{array}{l}\text { Absolute error } \\
\left(\mathrm{MJ} \mathrm{m} \mathrm{m}^{-2} \mathrm{~d}^{-1}\right)\end{array}$ & $\begin{array}{c}\text { Relative error } \\
(\%)\end{array}$ \\
\hline Bologna, Italy & 0.3 & 3.5 & 26.4 \\
\hline Bolzano, Italy & 0.8 & 3.6 & 27.8 \\
\hline Brindisi, Italy & 1.3 & 4.9 & 33.2 \\
\hline Castana, IA, USA & 1.1 & 5.1 & 30.4 \\
\hline Gainsville, FL, USA & 0.2 & 4.4 & 27.1 \\
\hline Gilat, Israel & 2.9 & 4.2 & 25.6 \\
\hline Los Baños, Philippines & -0.9 & 4.8 & 28.1 \\
\hline Joydebpur, Bangladesh & -0.1 & 4.5 & 29.2 \\
\hline Le Rheu Rennes, France & 0.3 & 3.8 & 28.6 \\
\hline Lethbridge, AL, Canada & 1.3 & 3.8 & 31.2 \\
\hline Lubbock, TX, USA & -0.2 & 4.6 & 27.0 \\
\hline Mandan, ND, USA & 0.5 & 3.9 & 28.2 \\
\hline Manhattan, KS, USA & 0.3 & 4.6 & 30.3 \\
\hline Nayink, China & -0.9 & 3.7 & 23.1 \\
\hline Palmaria, Colombia & -0.1 & 4.4 & 26.4 \\
\hline Quincy, FL, USA & 0.2 & 5.5 & 32.3 \\
\hline Samaru, Nigeria & -0.8 & 4.4 & 22.4 \\
\hline Sandhills, NE, USA & 0.6 & 4.6 & 30.3 \\
\hline Swifterbant, Netherlands & 0.6 & 2.6 & 29.2 \\
\hline Ustica, Italy & 1.6 & 4.9 & 31.4 \\
\hline Vigna di Valle, Italy & 0.9 & 3.8 & 26.3 \\
\hline Wageningen, Netherlands & 0.4 & 2.8 & 31.9 \\
\hline
\end{tabular}

Table 4. Absolute and relative error computed in the comparison between observed and estimated daily solar radiation in summer and winter periods. " Stations at which seasonal data were missing

\begin{tabular}{|c|c|c|c|c|c|c|}
\hline \multirow{2}{*}{ Station } & \multicolumn{3}{|c|}{ Summer } & \multicolumn{3}{|c|}{ Winter } \\
\hline & $\begin{array}{c}\text { Mean } \\
\text { difference } \\
\left(\mathrm{MJ} \mathrm{m} \mathrm{m}^{-2} \mathrm{~d}^{-1}\right)\end{array}$ & $\begin{array}{c}\text { Absolute } \\
\text { error } \\
\left(\mathrm{MJ} \mathrm{m}^{-2} \mathrm{~d}^{-1}\right)\end{array}$ & $\begin{array}{c}\text { Relative } \\
\text { error } \\
(\%)\end{array}$ & $\begin{array}{c}\text { Mean } \\
\text { difference } \\
\left(\mathrm{MJ} \mathrm{m} \mathrm{m}^{-2} \mathrm{~d}^{-1}\right)\end{array}$ & $\begin{array}{c}\text { Absolute } \\
\text { error } \\
\left(\mathrm{MJ} \mathrm{m}^{-2} \mathrm{~d}^{-1}\right)\end{array}$ & $\begin{array}{c}\text { Relative } \\
\text { error } \\
(\%)\end{array}$ \\
\hline Bologna, Italy & 0.8 & 4.5 & 22.4 & -0.1 & 2.2 & 31.9 \\
\hline Bolzano, Italy & 1.3 & 4.9 & 25.3 & 0.4 & 1.9 & 27.0 \\
\hline Brindisi, Italy & 1.5 & 5.9 & 27.2 & 1.1 & 3.2 & 38.5 \\
\hline Castana, IA, USA & 0.9 & 6.0 & 31.1 & 1.2 & 3.1 & 30.1 \\
\hline Gainsville, FL, USA & -1.2 & 5.3 & 26.7 & 0.7 & 3.5 & 29.1 \\
\hline Gilat, Israel & $\cdot$ & $\cdot$ & $\cdot$ & 2.0 & 4.0 & 29.5 \\
\hline Los Baños, Philippines & -1.3 & 4.3 & 24.7 & -0.8 & 4.9 & 29.9 \\
\hline Joydebpur, Bangladesh & -1.1 & 5.3 & 30.7 & -1.1 & 3.1 & 26.4 \\
\hline Le Rheu Rennes, France & -0.2 & 4.2 & 25.6 & · & $\cdot$ & $\cdot$ \\
\hline Lethbridge, AL, Canada & 2.0 & 4.9 & 27.5 & 1.2 & 1.2 & 20.6 \\
\hline Lubbock, TX, USA & -0.4 & 5.7 & 26.5 & 0.1 & 3.6 & 32.0 \\
\hline Mandan, ND, USA & -0.3 & 4.3 & 23.1 & 1.1 & 2.0 & 26.6 \\
\hline Manhattan, KS, USA & -0.1 & 6.1 & 29.0 & 0.7 & 3.2 & 33.0 \\
\hline Nayink, China & -0.9 & 3.8 & 21.8 & $\cdot$ & $\cdot$ & $\cdot$ \\
\hline Palmaria, Colombia & 1.7 & 4.0 & 25.7 & -1.2 & 3.9 & 22.3 \\
\hline Quincy, FL, USA & -0.3 & 6.3 & 30.0 & -2.0 & 4.0 & 35.7 \\
\hline Samaru, Nigeria & -1.1 & 4.2 & 22.2 & -1.7 & 4.1 & 21.0 \\
\hline Sandhills, NE, USA & 1.4 & 6.1 & 29.0 & 0.7 & 3.0 & 29.7 \\
\hline Swifterbant, Netherlands & 1.2 & 3.4 & 24.4 & 0.1 & 1.1 & 30.6 \\
\hline Ustica, Italy & 1.9 & 5.7 & 25.4 & 1.0 & 3.6 & 37.6 \\
\hline Vigna di Valle, Italy & 1.8 & 4.4 & 20.6 & 0.4 & 2.5 & 31.6 \\
\hline Wageningen, Netherlands & 0.6 & 3.7 & 26.7 & 0.2 & 1.1 & 30.2 \\
\hline
\end{tabular}


Table 5. Absolute errors of model and spatial interpolation methods. For each station the distance from the nearest weather station at which radiation is routinely measured is also given

\begin{tabular}{|lccc|}
\hline Station & $\begin{array}{c}\text { Absolute error } \\
\text { (MJ m } \mathrm{M}^{-1} \text { ) } \\
\text { Model }\end{array}$ & $\begin{array}{c}\text { Spatial int. } \\
\text { station } \\
\text { distance }(\mathrm{km})\end{array}$ \\
\hline Wageningen (NL) & 2.8 & 3.0 & 66 \\
Bolzano (I) & 3.6 & 4.4 & 151 \\
Bologna (I) & 3.5 & 3.7 & 118 \\
Vigna di Valle (I) & 3.8 & 4.8 & 180 \\
Brindisi (I) & 4.9 & 5.2 & 212 \\
Ustica (I) & 4.9 & 5.2 & 213 \\
\hline
\end{tabular}

1987). This model is based on existing theory and models of crop growth (de Wit 1978, Penning de Vries \& Van Laar 1982, van Kulen \& Seligman 1987) and requires, in addition to crop and soil parameters, daily data of minimum and maximum temperature, total daily global radiation, daily precipitation, average daily wind speed and air vapor pressure. It simulates wheat phenological development on the basis of degree-days (Porter 1984) and biomass growth as partitioned into root, stem, leaf and grain components. Crop yield, expressed as grain weight, is given as output at the end of the simulation. In the model, solar radiation is used as a driving variable in the calculation of potential evapotranspiration and crop photosynthesis. A sensitivity analysis of model response to changes in input radiation was conducted. Average reductions of 10,20 and $30 \%$ in input radiation led respectively to 8,16 and $26 \%$ decreases in calculated yields.

The model NWHEAT was run twice on the basis of weather data recorded at each station and year of observation included in Table 5. In the first run, observed weather data including daily global radiation were used as input. In the second run, the measured global radiation was substituted by estimates calculated using the discussed model. Yield predictions obtained in the 2 runs were then compared as illustrated in Fig. 3 in the form of a scatter diagram.

Calculated yields were observed to range, in both cases, from about $3 \mathrm{tha}^{-1}$ to about $9 \mathrm{tha}^{-1}$ and the amplitude of this range is a result of the very high variability that occurred in the weather conditions at the different stations and in the different years.

Yields calculated on the basis of the estimated irradiance do not markedly deviate from those calculated on the basis of observed values. The correlation coefficient between yields calculated in the 2 ways is 0.91 . The absolute error is $0.45 \mathrm{t} \mathrm{ha}^{-1}$ and the relative error is about $7 \%$.

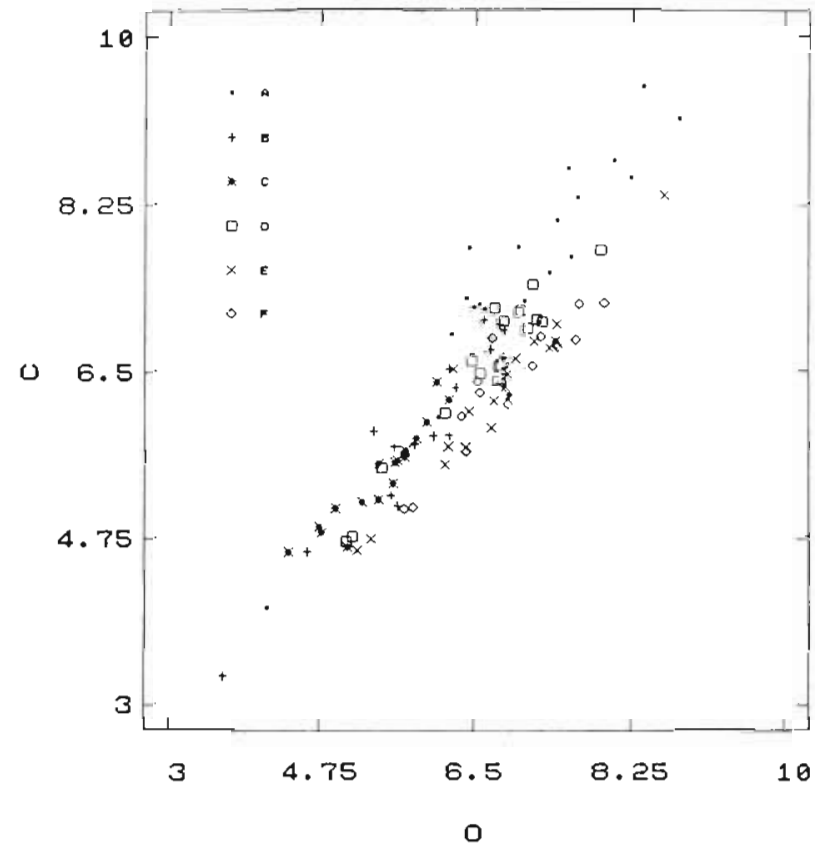

Fig. 3. Scatter diagram of wheat grain yields $\left(\mathrm{tha}^{-1}\right)$ computed by the use of observed (C) and estimated radiation (O). $\mathrm{A}=$ Wageningen (NL); $\mathrm{B}=$ Bolzano (I); $\mathrm{C}=$ Bologna (I); $\mathrm{D}=$ Vigna di Valle (I);E = Brindisi (I); F = Ustica (I)

\section{CONCLUSIONS}

Despite the very great simplification, the model here illustrated appears to be well suited for the estimation of daily global radiation records. The principal advantages of this model in respect to other estimation methods are:

- records of daily maximum and minimum temperature and total rainfall are the only weather data required;

- although long historical records of temperature and rainfall can improve the estimation accuracy they are not required;

- calibration parameters are not required;

- station parameters are directly derived from the latitude and from ancillary information concerning the climate of the region and the degree of urbanization/industrialization of the surrounding area.

Moreover, the model provides a simple and low cost system for estimating solar radiation. It does not require information from neighbouring stations for spatial interpolation and it does not require expensive hardware for data processing.

The model appears to be suited for most agrometeorological and simulation studies requiring solar radiation data and it can extend the effectiveness of these applications to areas where radiation is not or is only rarely measured by meteorological networks. 
Acknowledgements. The authors thank D. VanKraalingen, G. Hoogenboom and $\mathrm{R}$. Reginato for the weather data provided. J. J.R. Groot for the FORTRAN code of the NWHEAT model, G. Maracchi and G. Zipoli for discussion and an anonymous referee for useful suggestions

\section{LITERATURE CITED}

Atwater, M. A., Ball, J. T. (1978). A numerical solar radiation model based on standard meteorological observations. Solar Energy 21: 163-170

Bennet, 1. (1969). Correlation of daily insolation with daily total sky cover, opaque sky cover, and percentage of possible sunshine. Solar Energy 13: 391-393

Black, J. N., Bonython, C. W., Prescott, G. A. (1954). Solar radiation and the duration of sunshine. Q. J. R. Meteorol. Soc. 80: 231-235

Bristow, K. L., Campbell, G. S. (1984). On the relationship between incoming solar radiation and daily maximum and minimum temperature. Agric. For. Meteorol. 31: 159-166

Cano, D., Monget, J. M., Albuisson, M., Guillard, H., Regas, N., Wald, L. (1986). A method for the determination of the global solar radiation from meteorological satellite data. Solar Energy 37: 31-39

Cengiz, H. S., Gregory, J. M., Sebaugh, J. L. (1981). Solar radiation prediction from other climatic variables. Trans. A.S.A.E. 24 (5): $1269-1272$

Diabatè, L., Moussu, G., Wald, L. (1989). Description of an operational tool for determining global solar radiation at ground using geostationary satellite images. Solar Energy 42: $201-207$

Diak, G. R., Gautier, C., Masse, S. (1982). An operational system for mapping insolation from GOES satellite data. Solar Energy 28: 371-376

Dogniaux, R., Lemoine, M. (1976). Programme de calcul des éclairements solaires énergétiques et lumineux des surfaces orientées et inclinées. I.R.M. Misc. Série C, no. 14

Dogniaux, R., Lemoine, M. (1982). Classification of radiation sites in terms of different indices of atmospheric transparency. In: Palz, W. (ed.) Solar radiation data. Series F, Vol. 2. Reidel Publishing Company, Dordrecht, p. 94-105

Frulla, L. A., Gagliardini, D. A., Grossi Gallegos, H., Lopardo, R., Tarpley, J. D. (1988). Incident solar radiation on Argentina from the geostationary satellite GOES: comparison with ground measurements. Solar Energy 41: 61-69

Goudriaan, J. (1977). Crop micrometeorology: a simulation study. Simulation Monographs, Pudoc, Wageningen

Goudriaan, J. (1986). A simple and fast numerical method for the computation of daily totals of crop photosynthesis. Agric. For. Meteorol. 38: 257-262

Groot, J. J. R. (1987). Simulation of nitrogen balance in a system of winter wheat and soil. Simulation Report CABOTT no. 13, Centre for Agrobiological Research, Department of Theoretical Production Ecology, Wageningen

Haurwitz, B. (1948). Insolation in relation to cloud type. J. Meteorol. 5: 110-113

Hay, J. E., Suckling, P.W. (1979). An assessment of the networks for measuring and modelling solar radiation in British Columbia and adjacent areas of western Canada. Canadian Geogr. 23: 222-238

Hodges, T., French, V., LeDuc, S. (1985). Estimating solar

Editor: G. Esser radiation for plant simulation models. AGRISTAR, Technical Report USC-20239; YM-15-00403. (Obtainable from authors)

Justus, C. G., Paris, M.V. (1985). A model for solar spectral irradiance and radiation at the bottom and top of a cloudless atmosphere. J. appl. Meteorol. 24 (3): 193-205

Kasten, F., Czeplak, G. (1980). Solar and terrestrial radiation dependent on the amount and type of cloud. Solar Energy 24: $177-189$

Keulen, H. van, Heemst, van H. D. J. (1986). Meteorological data. In: Keulen, van $\mathrm{H}$., Wolf, J. (eds.) Modelling of agricultural production: weather, soils and crops. Simulation Monographs, Pudoc, Wageningen, p. 35-46

Keulen, H. van, Seligman, N. G. (1987). Simulation of water use, nitrogen nutrition and growth of a spring wheat crop Simulation Monographs, Pudoc, Wageningen

Kimura, K., Stephenson, D. G. (1969). Solar radiation on cloudy days. ASHRAE Trans. 75: 227-234

Lumb, F. E. (1964). The influence of cloud on hourly amounts of total solar radiation at sea surface. Q. J. R. Meteorol. Soc. 90: 383

Maracchi, G., Miglietta, F., Bacci, L., Romani, M. (1988). Metodi di stima della radiazione globale mediante la temperatura dell'aria. Boll. Geof. VI: 141-147

McCaskill, M. R. (1990). Prediction of solar radiation from rainday information using regionally stable coefficients. Agric. For. Meteorol. 51: 247-255

Nunez, M. (1987). A satellite-based solar energy monitoring system for Tasmania, Australia. Solar Energy 39: 439-444

Penning de Vries, F. W. T., van Laar, H. H. (1982). Simulation of plant growth and crop production. Simulation Monographs, Pudoc, Wageningen

Porter, J. R. (1984). A model of canopy development in winter wheat. J. agric. Sci. Camb. 102: 383-392

Richardson, C. W. (1981). Stochastic simulation of daily precipitation, temperature and solar radiation. Water Resour. Res. 17 (1): 182-190

Rimòczi-Paàl A. (1983). Determination of global radiation from satellite pictures and Meteorological data. Solar Energy 31: 79-84

Suckling, P. W. (1985). Estimating daily solar radiation values in selected mid-latitude regions by extrapolating measurements from nearby stations. Solar Energy 35: 491-495

Tabata, S. (1964). Insolation in relation to cloud amount and sun's altitude. In: Yohida, K. (ed.) Studies on oceanography. University of Tokyo, p. 202-210

Tarpley, J. D. (1979). Estimating incident solar radiation at the surface from geostationary satellite data. J. appl. Meteorol. 18: $1172-1181$

Turner, W. D., Abdulaziz, M. (1984). The estimation of hourly global solar radiation using a cloud cover model developed at Blytheville, Arkansas. J. appl. Meteorol. 23: 781-786

Wit, C. T. de (1970). Dynamic concepts in biology. In: Prediction and measurement of photosynthetic productivity. Proceedings IBP/PP Technical Meeting, Pudoc, Wageningen

Wit, C. T. de (1978). Simulation of assimilation, respiration and transpiration of crops. Simulation Monographs, Pudoc, Wageningen

World Meteorological Organization (1981). Estimation of solar radiation from measurements made at neighboring stations: In: Meteorological aspects of the utilization of solar radiation as an energy source. WMO Technical Note no. 172, Geneva, p. 189-204

Manuscript first received: June 20, 1990

Revised version accepted: December 18, 1990 